REVISTA DE GESTÃO ESECRETARIADO

MANAGEMENT AND AdMINISTRATIVE

PROFESSIONAL REVIEW

ISSN: 2178-9010
Revista GeSec

São Paulo, SP, Brasil

v. 12 , n. 1 , p. $160-177$

jan. /abr. 2021

DOI: http://dx.doi.org/10.7769/gesec.v12i1.1125

\title{
Engrenagens e extensões do corpo feminino: a mulher ciborgue no trabalho
}

\section{Gears and extensions of the female body: the cyborg woman at work}

\author{
Karine Freitas Souza ${ }^{1}$
}

\section{Resumo}

Profissões "femininas" exigiram conhecimentos sobre as tecnologias dos escritórios nos séculos XX e XXI. As secretárias quase sempre foram representadas em relações "amorosas" com estas máquinas. Considerando tais informações, perguntamo-nos: quais as relações existentes entre mulheres trabalhadoras, em particular, secretárias, e as tecnologias em escritórios manifestas na ficção dos filmes? Este trabalho objetiva realizar uma breve análise, a partir do Manifesto Ciborgue de Donna Haraway (2013), sobre como as tecnologias atuaram na condição de engrenagens e extensões do corpo das secretárias nos filmes. No tocante à abordagem, o estudo é qualitativo; quanto aos objetivos, ele é exploratório e, por fim, quanto aos procedimentos técnicos adotados, tem-se que ele é documental e bibliográfico. Com base nas análises realizadas, foi possível perceber que as mulheres representadas nas ficções cinematográficas analisadas neste trabalho podem ser consideradas ícones ciborgues sob a perspectiva do Manifesto Ciborgue.

Palavras-chave: Mulheres. Ciborgue. Tecnologia. Filmes.

\section{Abstract}

"Female" professions required knowledge of office technologies in the 20th and 21st centuries. Secretaries have always been represented in "loving" relationships with these machines. Considering such information, we ask ourselves: what are the relationships between working women, in particular secretaries, and the technologies in offices manifested

\footnotetext{
${ }^{1}$ Doutora em Ciências Sociais, docente no Mestrado Profissional em Segurança Pública, Justiça e Cidadania PROGESP da Universidade Federal da Bahia (UFBA).
} 
in the fiction of films? This work aims to make a brief analysis, from Donna Haraway's Cyborg Manifesto (2013), on how the technologies acted in the condition of gears and extensions of the body of desks in films. Regarding the approach, the study is qualitative; regarding the objectives, it is exploratory and, finally, regarding the technical procedures adopted, it must be documentary. Based on the analyses made, it was possible to realize that the women represented in the cinematographer's fictions analyzed in this work can be considered Cyborg icons from the perspective of the Cyborg Manifesto.

Keywords: Women. Cyborg. Technology. Movies.

\section{Introdução}

Transformações sociais decorrentes do desenvolvimento tecnológico, ou vice-versa, implicaram não somente em novos conhecimentos e habilidades na sociedade ocidental, mas também em desafios de empregabilidade. A relação entre tecnologia e seres humanos estreitou-se para uma simbiose que gerou também novos espaços para conexões entre o que se faz e o que se é. Sob a forma de íntimas relações entre pessoas e máquinas, dentro e fora dos ambientes de trabalho a tecnologia é cada vez mais presente e indissociável do Ser e do Fazer expondo, por sua vez, a existência de fronteiras tênues e de difíceis distinções derivadas dessas realidades sociais entre pessoas e máquinas.

Este trabalho produziu um breve olhar qualitativo e de cunho interpretativo sociológico, na perspectiva do trabalho, sobre criaturas de ficção cinematográfica, no contexto do secretariado, ao evidenciar a inexistência de neutralidades entre pessoas e tecnologias, pois essas relações têm como objetivo o máximo proveito para atender o capital. Com base em tais informações, procura-se responder a seguinte questão-problema: quais as relações existentes entre mulheres trabalhadoras, em particular, secretárias, e as tecnologias em escritórios manifestas na ficção dos filmes?

Nesse sentido, compreende-se que as mulheres desenvolveram forçosas interações com o aparato mecânico e tecnológico nos escritórios também como via de acesso a eles. Sob a perspectiva do Manifesto Ciborgue de Donna Haraway (2013) foram analisadas algumas das relações entre mulheres trabalhadoras, em particular, secretárias, e as tecnologias em escritórios manifestas na ficção dos filmes considerando as redes e as fronteiras dos chamados territórios da produção, da reprodução inorgânica e da imaginação. A análise recaiu sobre 
algumas personagens do cinema, para compreender como a tecnologia pode ser entendida como uma extensão do corpo feminino.

O artigo está estruturado da seguinte forma: inicia-se com esta breve introdução, cujo foco é contextualizar o leitor do assunto em discussão; depois, segue-se com o referencial teórico na intenção de trazer algumas fundamentações científicas para o estudo. Na sequência, apresentam-se os aspectos metodológicos do trabalho e inserem-se os resultados e discussões. Por fim, tem-se as considerações finais e listam-se as referências utilizadas na confecção deste texto.

\section{Referencial Teórico}

\subsection{Umpatchwork entre o mito ciborgue e as mulheres}

A tradição filosófica ocidental cunhou matrizes conceituais sobre o Ser indissociáveis com o Fazer. Sob a perspectiva de Donna Haraway (2013) o Ser e o Fazer assumem novas configurações ao possibilitar outras representações de matéria de ficção e de experiências vividas nas relações entre as pessoas, suas identidades e suas realidades. Além disso, são as redes, as conexões com o novo mundo que experenciam e, principalmente, os espaços onde ocorrem as interações entre pessoas-máquinas-tecnologias, que contribuem para a formação de novas identidades pós-humanas. Para esses novos humanos, as tecnologias, o acesso e difusão da informação cooperam e vão além da inserção e manutenção dos trabalhadores no mundo capitalista.

O conceito de Haraway (2013) sobre as novas perspectivas de identidades em um mundo tecnológico consegue traduzir como estas são construídas: por meio das relações e simbioses, emprestando-se o termo e conceito da biologia, entre os seres humanos, as máquinas, as tecnologias e as informações. São nas inevitáveis interações diárias e não somente com os dispositivos tecnológicos, mas, principalmente, com as políticas de tecnologização que determinam a vida e colaboram para o surgimento das novas identidades, que surgem os novos sujeitos, os ciborgues. O caráter simbólico do mito proposto por Haraway (2013) foca-se essencialmente na provocação e desenvolvimento de ações políticas em que a sua apregoada existência dos ciborgues é uma forma de subversão, uma provocação que visa à instabilidade, o questionamento de identidades, de gênero, de políticas e contextos histórico-sociais e econômicos. Em suma, o híbrido proposto por Haraway (2013) é o humano 
produzido pelas suas íntimas relações com o mundo construído tecnológico e informacionalmente na Sociedade Ocidental.

Historicamente o acesso das mulheres às empresas ocorreu por inúmeros fatores sociais, políticos e econômicos. De modo geral, a inserção feminina nas empresas esteve condicionada não somente à disponibilidade dos postos de ocupação, mas também a determinantes em que o gênero condizia sempre com a aceitação de trabalhos em condições desumanas e vergonhosas (Beauvoir, 1980, p. 148-149) e o enclausuramento em profissões mal pagas e subordinadas (Nye, 1995, p. 38-53). As mulheres foram aprisionadas pela dependência econômica em que viviam em relação aos homens, isso com tanta certeza quanto os robôs são controlados pela ameaça implícita de que seus senhores podem sempre cortar o suprimento de energia, apertar o botão liga-desliga, deixá-los onde estão ou devolvê-los à prateleira (Plant, 1999, p. 100).

Quaisquer que tenham sido os motivos que possibilitaram a inserção e permanência das mulheres nos trabalhos burocráticos não se pode esquecer que estes sempre visaram atender as necessidades de produção do capital. Em consonância com a modernidade a tecnologização das empresas terminou por criar laços mais do que interativos entre as mulheres e as "máquinas pré-cibernéticas", ratificadas por Haraway (2013, p. 41). Conforme Plant (1999) isso ocorreu desde sempre confirmando que as relações entre mulheres e os aparatos tecnológicos constituem precisamente um "casamento" com as máquinas (Perrot, 2005).

Neste estudo, um olhar sobre as mulheres, secretárias na ficção, exprime algumas dessas relações "matrimoniais". De acordo com Natalense (1998), Plant (1999) e Perrot (2005) a máquina de escrever é considerada uma das tecnologias de acesso das mulheres aos postos de trabalho administrativo nas empresas. Em 1873 o inventor de uma dessas máquinas Charles Sholes colocou sua própria filha, Lilian Sholes, para testar a máquina em público. Na época Lilian tinha catorze anos de idade e foi a primeira mulher a realizar tal feito publicamente (Natalense, 1998). Ao pensar sobre sua invenção Charles Sholes declarou: "acho que fiz alguma coisa pelas mulheres que sempre tiveram que trabalhar tão arduamente" (Plant, 1999, p. 111).

A análise dos dois livros clássicos da área secretarial das décadas de 1960 e 1970, o Curso de Secretariado Executivo, de Olga Rainho (1970), e o Manual da Secretária Moderna, de Helena Montezuma [entre 1950 e 1960], evidenciou que essas publicações contribuíram para a formação de secretárias, mas com diversas recomendações que julgamos serem questionáveis. Grande parte dos textos dessas autoras tratavam de assuntos como: 
posturas no escritório, etiqueta, cuidados com o corpo e a aparência (uso de cosméticos, higiene íntima etc.), o trato com a família do chefe e o trato com a própria família daquela que passava muito tempo fora do lar. Montezuma [entre 1950 e 1960] chamava atenção para os cuidados com as tarefas domésticas para que pudesse dar conta da dupla jornada, na atenção ao marido, filhos e das múltiplas tarefas do lar sem que estas interferissem em sua produtividade no trabalho.

Condizente com o pensamento da sociedade ocidental daquele tempo, Montezuma [entre 1950 e 1960] evidenciava que a atitude de uma secretária deveria ser a de uma "senhora" (termo que entendemos ser usado no sentido de respeitabilidade) que presta serviços "humildes". Essa afirmação explicitava e reproduzia o real valor da atividade secretarial, do trabalho e das mulheres. Os dois livros também apresentavam os termos "moças", "jovens" e até mesmo "mocinhas". Em todas as recomendações sobre o lar, o trabalho, a higiene pessoal, as roupas a usar e demais detalhes pessoais e profissionais estão explícitas condições para ser secretária: juventude e beleza, elementos que contavam para o desempenho da profissão, ratificando, assim, as afirmações de Wolf (1992) quanto ao Mito da Beleza.

No próximo tópico deste referencial teórico, buscamos traçar um paralelo entre as mulheres, as máquinas e o trabalho, de modo que seja possível perceber a conexão desses elementos com o mito ciborgue.

\subsection{Mulheres, máquinas e trabalho: flertando com o mito Ciborgue}

A máquina de escrever realmente possibilitou a inserção da mulher nos trabalhos administrativos em definitivo. Os números de empregadas em escritórios nas primeiras décadas do século XX, apresentados por Benét (1975), Perrot (1998) e Plant (1999), representaram milhões de postos de trabalho em curva crescente. Uma massa de mão-de-obra feminina que ocupou diversas posições relacionadas aos usos dos aparatos tecnológicos. Perrot (2005, p. 224) explica que "as datilógrafas, necessariamente graciosas, expulsam progressivamente os copistas com jeito de clérigos e fazem ruir o velho apanágio do escriba: o apanágio do manuscrito e da escrita". O autor corrobora essa informação ao dizer que:

a iconografia, a publicidade, sobretudo divulgam estas novas imagens da mulher e do casal amoroso que ela forma com sua Singer ou com a Remington. Da máquina de escrever, diz-se que ela é, logicamente, a sequência do piano. Entre as novas tarefas às quais a moça parece adaptar-se admiravelmente, é preciso citar as de estenografia e datilógrafa (Perrot, 2005, p. 226-227). 
Não por acaso são diversas as imagens da publicidade em que máquinas de escrever estão quase sempre associadas às mulheres, conforme Figura 1.

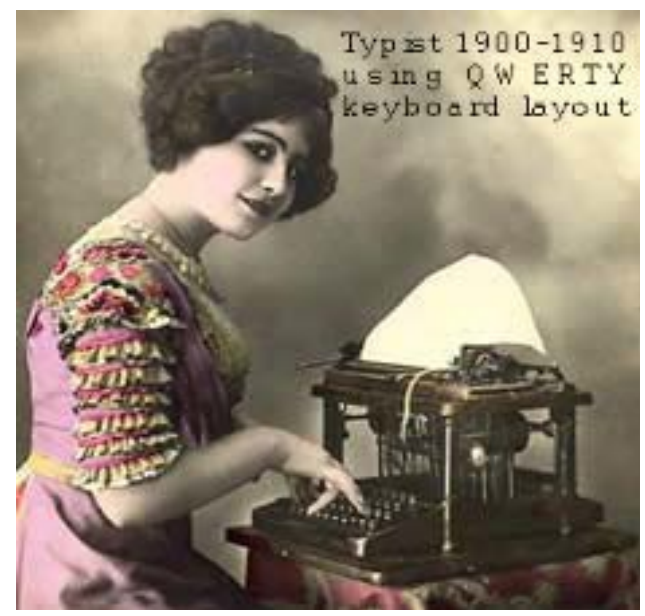

Figura 1. Datilógrafa do início do século XX Fonte: Powertyping (2013).

São históricos os concursos locais, regionais e nacionais de datilografia do século XX (Figura 2), conforme descrições em Perrot (1998), onde hordas de mulheres eram testadas por suas exímias habilidades datilográficas como descrito em Plant (1999).

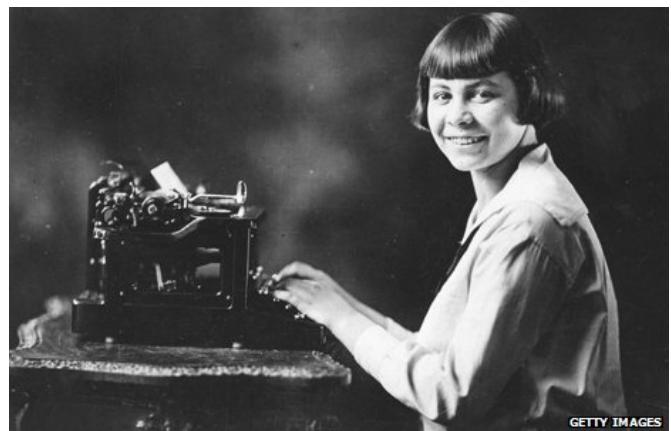

Figura 2. Birdie Reeve Kay, campeã de um concurso nos EUA após datilografar mais de 200 palavras por minuto

Fonte: BBC News (2013).

A relação entre as mulheres e a datilografia instituiu-se também pelas condições socioeconômicas dessas que as impulsionou ao trabalho fora do lar. Perrot (1998, p. 101) cita que havia uma escola francesa de estenodatilografia com o seguinte slogan: "Se você não pode dar um dote às suas filhas, mande-as à escola Pigier”. A relação entre condição social da mulher e o trabalho também foi utilizada em reclames de cursos de datilografia e secretariado no Brasil. Um deles publicado pelo jornal "Estadão", em 17 de março de 1918, mostrava uma mulher datilografando e a sugestiva chamada: “Sois pobre?", conforme Figura 3. 


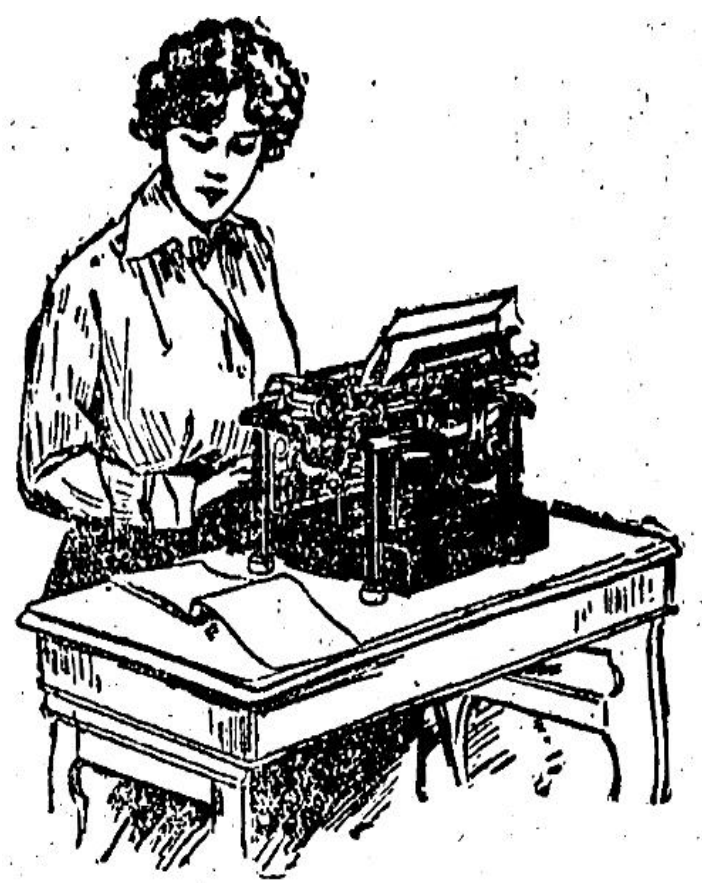

\section{Como se começa}

Sois pobre?

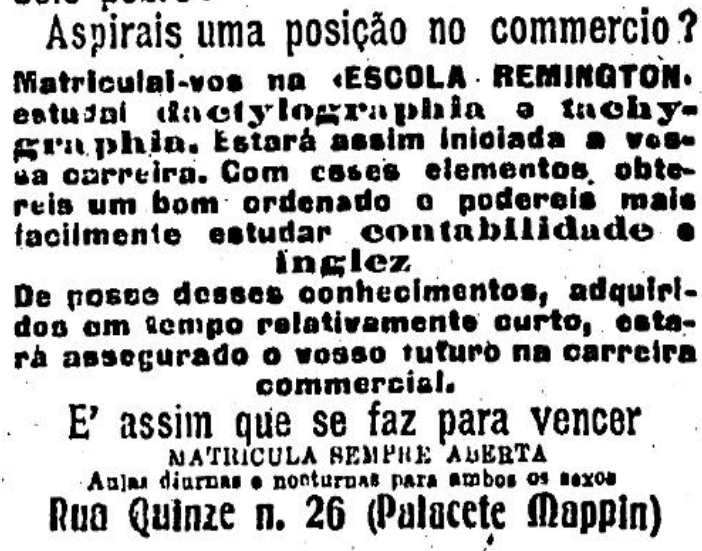

Figura 3. Reclame de uma escola de datilografia Fonte: Estadão (2019).

As escolas de datilografia e de secretárias ensinavam os padrões rítmicos e os usos da máquina. A perícia das mulheres era julgada pela velocidade conforme Plant (1999, p. 112). Absorvida como uma das principais práticas secretariais, a datilografia deveria ser plenamente desenvolvida pela secretária. Sousa (2006) afirma que é possível compreender a imagem inicial da mulher no escritório, em especial, a secretária, sempre vinculada ao maquinário e à atividade manual em detrimento da atividade intelectual, sob a afirmação de Perrot (2005): esta era uma forma de recusar outra qualificação à mulher e valorizá-la apenas por sua destreza mecanográfica negando o acesso à ciência. Segundo Montezuma [entre 1950 e 1960] a secretária deveria saber dar manutenção à máquina de escrever e recomendava, por exemplo, espaná-la diariamente antes de sua utilização. Outra recomendação indicava como 
livrar-se da tinta nos dedos resultante dos carbonos utilizados nas máquinas. Para além do contato físico com as máquinas, as relações entre os seres humanos e estas podem ser entendidas em um nível em que:

As máquinas do século XX tornaram completamente ambíguas a diferença entre o natural e o artificial, entre a mente e o corpo, entre aquilo que se autocria e aquilo que é externamente criado [...] nossas máquinas são perturbadoramente vivas, e nós mesmos, assustadoramente inertes (Haraway, 2013, p. 42).

Nesse sentido, a relação entre mulheres e as máquinas de escrever ocorre pela inércia sob a perspectiva de Plant (1999, p. 110-111), que definiu ser a máquina de escrever capaz de prover a princípio "um escriturário novo e melhorado". Isso explica em parte as hordas de mulheres que ascenderam aos escritórios como datilógrafas e secretárias, mas ainda assim perpetuando a subordinação patriarcal das mulheres nessas profissões e distando da ciência como predito por Perrot (2005). As secretárias congregaram entre suas habilidades e afazeres, as atividades de datilografia e estenografia, disciplinas presentes até a metade da década de 1990 nos currículos acadêmicos de universidades federais do Brasil, onde havia o curso de Secretariado Executivo, como, por exemplo, na Universidade Federal da Bahia (Sousa, 2006).

Montezuma [entre 1950 e 1960] e Rainho (1970) recomendavam que o aprendizado da profissão devesse se basear nos exemplos de secretárias há mais tempo na atividade e na observação das personagens secretárias do cinema e do teatro. Entre os aconselhamentos a secretária deveria buscar sempre "imitar" apenas os bons modelos da mídia. Ora, sobre a arte cinematográfica os filmes norte-americanos não foram certamente os melhores exemplos a serem observados. Por sua vez, Perrot (1998, p. 249) afirma que muito distantes da massa das mulheres dos países em desenvolvimento, os modelos e mídia ocidentais não têm necessariamente afinidades e as secretárias podem ser espontaneamente hostis a eles. Por outro lado, observa-se que os modelos difundidos pela mídia exercem um real poder de atração, especialmente sobre as populações urbanas, embora se trate mais de modelos de consumo do que de acesso a novos papéis públicos.

Diante dessa relação histórica entre mulheres e máquinas foi necessário decidir por uma metodologia que dialogasse sociologicamente com os sujeitos e contemplasse a tessitura do trabalho secretarial sob uma perspectiva ciborgue. 


\section{Metodologia}

No tocante à abordagem, o estudo é qualitativo; quanto aos objetivos, ele é exploratório e, por fim, quanto aos procedimentos técnicos adotados, tem-se que ele é documental e bibliográfico. Neste estudo, optou-se por compreender como as mulheres tornaram-se parte do mito Ciborgue nos escritórios, sob um olhar inclusivo que acatou também o cyberfeminismo de Plant (1999), em que a historicidade sobre as relações e interações entre mulheres e máquinas devem ser consideradas. As análises recaíram sobre os conteúdos textuais e imagéticos possuindo cunho interpretativo sob o viés da sociologia do trabalho e do feminismo (na perspectiva do mito ciborgue). Para tanto, a seleção das peças publicitárias e dos filmes foram adquiridas, descritas no todo ou em partes. Os critérios para busca dos filmes se deram a partir da proximidade deles com o mito ciborgue. Considerando o contexto histórico, seus conteúdos foram analisados e interpretados à luz das teorias aqui referenciadas.

Como resultado dessas seleções, tivemos os filmes Blade Runner (Scott, 1991) e Populaire (Roinsard, 2013). Tal como já adiantado, esta apuração ocorreu por serem estes meios os que apresentavam relação com o propósito da pesquisa, ou seja, continham traços do que seria a mulher ciborgue no trabalho secretarial. Os filmes a serem selecionados deveriam possuir proximidades relativas, pois utilizam narrativas, contextos, diálogos, cores, luz e ações que instigam os leitores a uma participação no mínimo interpretativa.

No caso das mulheres ficcionais, sujeitas da pesquisa, foi necessário considerar o pensamento de Haraway (2013) para quem as fragmentações identitárias as distanciam de uma localização comum enquanto categoria única, e as tornam antagônicas em suas próprias "epistemologias e taxonomias do feminismo" (Haraway, 2013, p. 49-52). Por esse aspecto as mulheres analisadas neste estudo distam em maior ou menor proporção de um padrão ou unicidade que seriam comuns aos sujeitos de uma pesquisa. Esta é uma questão própria à crítica quanto ao "uso monolítico da categoria mulher" afirmado por Garcia (2011, p. 94).

A crítica característica do feminismo da década de 1980 consolida a necessidade de centrar esforços na diversidade entre mulheres. Assim, o que as categoriza é o trabalho, em especial, secretarial (Zuin \& Findlay, 2014; Oliveira, 2016, Sousa, 2017): Por distar do que seria a "matriz identitária natural" e por ser "uma categoria ontológica que possibilita o conhecimento do sujeito e, assim, o conhecimento da subjugação e da alienação", conforme Haraway (2013, p. 53), ao permitir, portanto, que pelo trabalho sejam identificadas algumas ciborgues, secretárias, no campo das artes cinematográficas. 


\section{Análise e Discussão dos Resultados}

\subsection{A datilógrafa ciborgue no Cinema - Populaire}

O filme Populaire, de Régis Roinsard, recebeu o nome de A Datilógrafa, no Brasil. O filme conta a história de uma jovem de 21 anos, chamada Rose Pamphyle, interpretada por Déborah François, que vive com o pai e está prestes a se casar com o filho de um garagista. $\mathrm{Na}$ sinopse do filme a moça recusa o destino de dona-de-casa pela sua ambição em ser secretária. Ela sai da pequena loja familiar e tenta um emprego de datilógrafa em um escritório de seguros dirigido por Louis (Romain Duris). A personagem Rose demonstra a princípio ser inapta para a atividade secretarial, mas impressiona o empregador por sua velocidade de digitação. Seu chefe enxerga em sua habilidade manual e em sua destreza datilográfica uma oportunidade para que ela participe e ganhe uma competição nacional de datilografia (Cineclick, 2013).

Estão presentes no filme os estereótipos de romance-sexo entre o chefe e a secretária. $\mathrm{Na}$ cena de seleção para vaga de secretária, 24 candidatas suspiram, arrumam as roupas, ajeitam a maquiagem e mudam a postura visando impressionar pela aparência. Uma delas chega a afirmar: "Tudo está na aparência", ao passo que outra secretária confirma: "Na boa aparência". Durante a entrevista a personagem principal diz: "A única coisa que faço bem é datilografar". Ela assume sua relação com a tecnologia, que a princípio é questionada e assediada moralmente pelo chefe pela forma inadequada como datilografa, sem técnica e sem o uso de todos os dedos. Ele lhe diz: "use todos os dedos, você não tem talidomida".

O filme reproduz em sua essência, cenas e peças publicitárias que remontam as "novas redes de mulheres e máquinas" (Plant, 1999, p. 110). E reforça também, como tantos outros filmes sobre secretárias, os estereótipos da profissão incluindo o romance entre chefesecretária e a relação de dominação (Figura 4). 


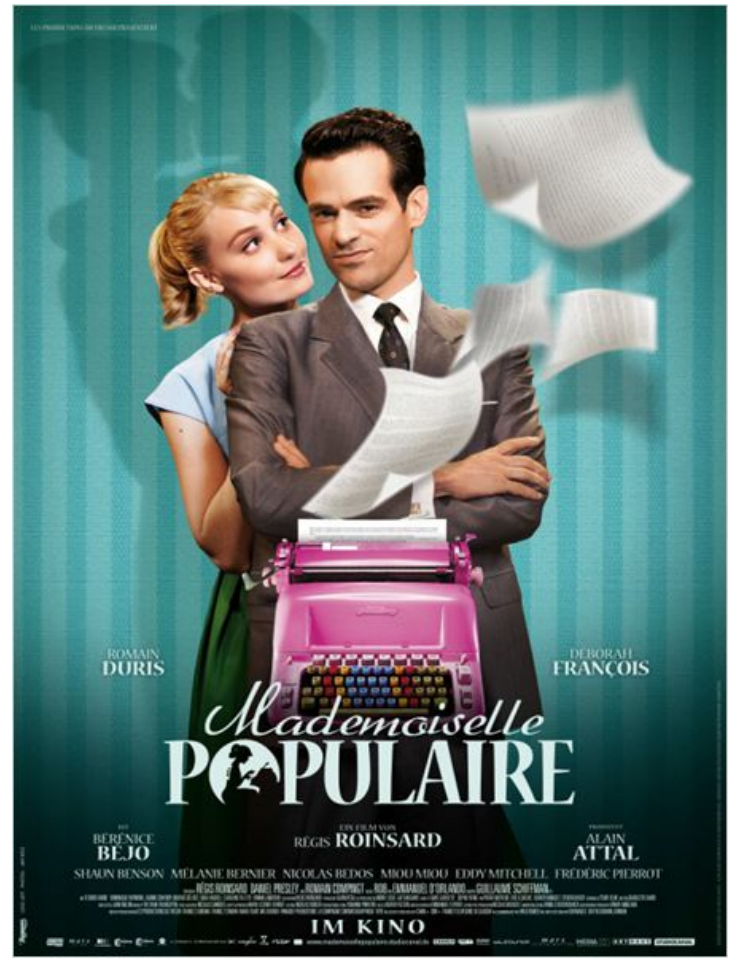

Figura 4. Pôster do filme Populaire Fonte: Moviepilot (2013).

Em dois pôsteres promocionais do filme as imagens são semelhantes. Mudam apenas as cores de fundo e algumas pequenas disposições de tamanho. No pôster analisado, a imagem em primeiro plano coloca o chefe frente à secretária reforçando a ideia do homem frente à mulher. Ao fundo, as sombras dos dois mostram que eles estão a ponto de se beijar. Assim, desde a chamada publicitária se reafirmam a dependência da mulher em relação ao homem no trabalho secretarial, sua subordinação, a idealização de romance ou de encontro sexual no trabalho, reforçando os estereótipos para com as mulheres secretárias.

Em diversas cenas, a personagem evidencia sua relação com a máquina como uma extensão do corpo. Os treinos extenuantes fazem com que todo seu corpo doa. A fim de aprimorar a técnica e ter mais agilidade, ela aprende a tocar piano. Também muda sua rotina de vida e integra exercícios físicos para melhorar o desempenho com a máquina. Em dado momento, exaurida, a personagem queixa-se: "Não posso ser mais rápida que a máquina”.

Outro cartaz do mesmo filme (Figura 5) apresenta várias mãos sobrepostas que escondem os olhos da datilógrafa. Essas mãos aludem à sua extrema velocidade na datilografia, mas essencialmente também remetem a uma mulher "monstro", cujas capacidades de ajuste à máquina e desempenho devem ser excepcionais. 


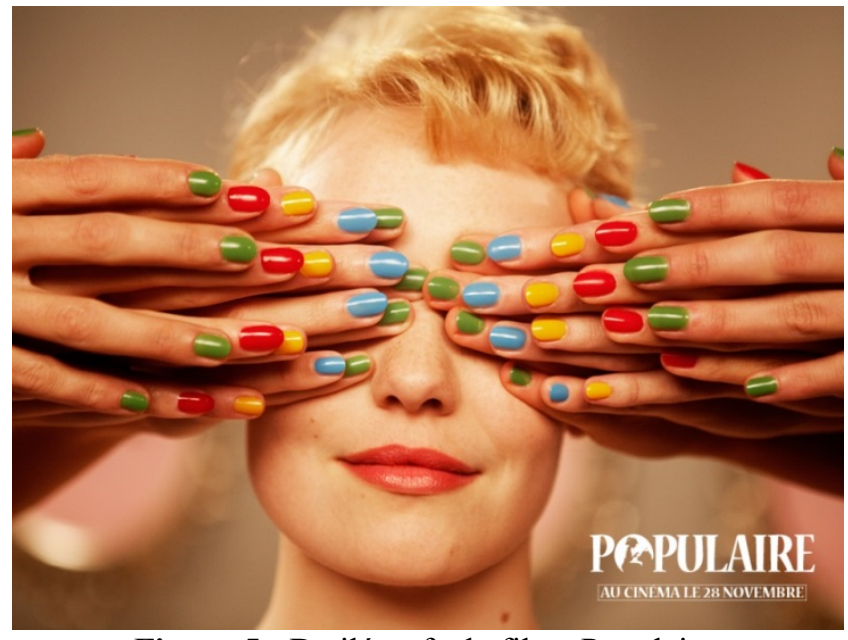

Figura 5 - Datilógrafa do filme Populaire. Fonte: Encantes (2016).

Esta peça publicitária reproduz fielmente a afirmação de Plant (1999, p. 111) para quem o trabalho nos escritórios dependia das relações e interações entre mulheres e máquinas, habilidades de destreza e velocidade e, sobretudo, ao considerar que "Os dedos das mulheres eram mais esguios e mais baratos do que as velhas mãos alugadas". O cartaz em questão tem seu duplo na cena em que a personagem como garota propaganda apresenta a nova máquina de datilografia, cor de rosa, na televisão. No filme estão embutidas afirmações sobre a tecnologia. Em determinada cena Rose Pamphyle diz: "Acho que a velocidade é sinal de progresso. Um dia o mundo será cheio de teclado".

De fato, a profissão de secretária era o caminho mais fácil para a mulher que desejava trabalhar fora de casa, com livre (até certo ponto) acesso às organizações, caso demonstrasse as qualidades necessárias, conforme afirmações de Perrot (1998). Haveria sucesso desde que seguissem as recomendações quanto aos estudos, aprimoramento técnico e proficiência nos idiomas (Montezuma, [entre 1950 e 1960]). Ainda assim, a confusão de papéis dentro e fora do lar era latente. Em nossos estudos, tanto as comparações feitas por Montezuma [entre 1950 e 1960] quanto às orientações de Rainho (1970), afirmavam que as secretárias deveriam aterse aos cuidados da limpeza e asseio do ambiente de trabalho, definindo ser responsabilidade de uma secretária limpar inclusive os cinzeiros, sempre que necessário. Ora, sob tais recomendações a secretária desempenhava uma função análoga à de uma dona-de-casa, o que evidencia que mesmo trabalhando em empresas, as mulheres não eram vistas como profissionais e tampouco consideradas como tais. Havia nesse tipo de publicação (manuais técnicos de secretariado) recomendações para que as secretárias exercitassem seu dom excepcional e divino do sexto sentido, que lhes permitiria prever o que fazer, como e quando. 
A mudez nos momentos adequados também era explicada como uma postura profissional esperada para a secretária.

Perrot (2005) considera a área de secretariado um campo profissional com papel importante na história da mulher, pois para ela seriam as secretárias que começariam a verdadeira mutação do trabalho feminino nas organizações. Talvez por possuírem um pouco mais de acesso às informações? Parece que, sim, pois em Plant (1999, p. 114) "supunha-se que secretárias e estenógrafas apenas processassem informações que haviam sido produzidas e organizadas em outro local". Mas sabe-se que as secretárias são educadas para coletar, organizar dados e processá-los, transformando-os em informações.

Nos manuais das décadas de 1960 e 1970, as secretárias aprendiam o uso do telefone, da linguagem, da correspondência, da transcrição de ditados, da estenografia, da datilografia e dos equipamentos de escritório, como calculadoras e máquinas de escrever. Conforme ocorreu o avanço tecnológico, outros equipamentos foram introduzidos no escritório e passaram a fazer parte das relações entre mulheres-secretárias e máquinas. Foi assim com o telex, o facsímile, os computadores e todos os demais aparelhos que fomentavam os trabalhos administrativos. Não por acaso são também comuns as imagens de secretárias ao lado de suas máquinas de escrever e telefones. E sobre o último, este "brinquedo eletrônico" foi percebido como parte de uma grandiosa rede de comunicação, e de imediato tornou-se alvo para os usos da mão-de-obra feminina, sempre extensa e mais barata, pois o telefone se constituiu em mais uma peça importante no patchwork do ciborgue, já que o futuro era vinculado diretamente às pontas dos dedos e onde "Basicamente, você, srta. Luthor, é o 'sistema de relés'." (Plant, 1999, p. 112). Até onde as relações entre as mulheres e as máquinas poderiam avançar?

\subsection{A literal ciborgue secretária}

Nos anos 1980 o filme Blade Runner marcou época ao tratar da tecnologia sob a aparência humana, no ser que chamou de replicante. Ciborgues criados à imagem e semelhança do homem, em um nexo e alusão à criação divinizada deste. O filme, um cult cinematográfico, transitava em torno de uma sociedade povoada também por andróides, chamados de replicantes. Puhl e Amaral (2008) destacaram as subjetividades femininas da replicante Rachel, uma ciborgue que, na trama desempenha o papel de secretária, naturalmente secundário frente à sua real posição no filme: o de moça em crise existencial que necessita ser salva por um homem. O agente Deckard, interpretado pelo ator Harrison Ford, ocupa o papel principal como um caçador de replicantes. Sobre ele recai a suspeição quanto a 
sua verdadeira natureza ao ser provocado por Rachel: Seria ele um replicante? Já havia sido testado pela mesma tecnologia que utilizava para identificar os replicantes que caça? Provocações da Rachel ao Deckard.

A secretária replicante atende ao criador dos ciborgues, o senhor Tyrell. No papel de secretária ela reproduz os estereótipos da profissão, tais como: subserviência, feminilidade, beleza, juventude baixo a tutela de um homem, seu idealizador. A identidade feminina desta ciborgue é observável, portanto, sob três dimensões:

\begin{abstract}
Submissão - os ciborgs, na condição dos escravos, são submissos a esses, assim como as mulheres foram e, em alguns países, ainda são submissas aos homens. E todo o imaginário construído a partir daí contribui para essa colocação da mulher como ser submisso ao controle.

Sentimentos - a mulher por meio dos sentimentos, destacando o amor, potencializa a tríplice do C3 (comando-controle-comunicação) e assim se faz Inteligente, pois através do amor ele conquista a sua sobrevivência a partir outro (masculino). Em Blade Runner a frágil Rachel é salva por Deckard, pois ele a amava e por isso a protegeria da extinção. Os ciborgs femininos fazem da relação homem/mulher a sua força e não uma fraqueza, construída pelo arquétipo do "sexo frágil" legitimado pela cultura ocidental. O amor é desconstruído, ele funciona como fronteira e não como dualista ou pertence ao bem ou ao mal, ele é dialético.

Alteridade - A alteridade, na ficção-científica, seja ela um alienígena, uma máquina dotada de inteligência artificial ou um robô, representa o duplo ao homem. Posta diretamente em conflito com o humano, a alteridade suscita questionamentos, assim como a própria validade, identidade e existência do ser humano enquanto tal, em uma relação com a identidade feminina, esta é alteridade do masculino, fazendo com que a mulher sinta-se "o outro" na cultura ocidental, como diz Haraway (1994, p. 283) "prefiro ser um ciborg a uma deusa" (Puhl \& Amaral, 2008 p. 12-13).
\end{abstract}

Em relação à profissão de secretário, a replicação ciborgue ocorreu inicialmente como uma mimese tratada por Plant $(1999$, p. 114), quando explicou que a secretária era a "segunda pele" do patrão e era também:

A voz, o sorriso, a interface do chefe, ligando-o com o mundo e protegendo-o contra ele, a tela na qual ele se apresentava, uma fachada, superficial, um filtro do processamento, um escudo, uma vestimenta protetora (Plant, 1999, p. 114).

A secretária era uma espécie de "duplo" cujos segredos e confidencialidades de vida pessoal e profissional eram falados, tratados e assinados por ela, desde que sua assinatura fosse sempre precedida pelo nome da chefia e sua identificação incluísse as letras "pp". Tratase também de um simulacro no sentido proposto por Baudrillard (1991, p. 152) quanto à geração de modelos. Em nossa análise a replicação ciborgue da mulher secretária segue também pela via da educação; pelos estímulos aos conhecimentos, o domínio de aplicativos, o domínio dos editores eletrônicos, aos usos dos aparatos tecnológicos nos ambientes de trabalho; na compreensão dos usos e funcionamentos das redes de comunicações (internet, intranet, telefonia, rádio, etc.), na geração de informações e nas relações e interações entre humanos e tecnologias. Não existe secretária sem a tecnologia, tampouco existe uma imagem

Revista Gestão e Secretariado (GeSec), São Paulo, SP, 12(1), jan./abr., 2021, p. 160-177. 
da secretária sem as suas extensões tecnológicas, pois sem elas o seu trabalho é deslocado de sentido e fora de contexto. Muito dessas premissas se mantêm atualmente.

A partir do século XX o número expressivo e quase absoluto de mulheres ocupando a atividade secretarial manteve-se em um crescente e faz com que, ainda hoje, em pleno século XXI, as mulheres sejam maioria na profissão.

O filme reproduz mitos como o amor romântico e o príncipe que salva a princesa, já que Rachel é "salva" da morte pelo amor do homem, ou ciborgue? Qualquer que seja a natureza do herói na trama, homem ou homem-ciborgue, fica claro nesta obra cinematográfica que a mulher-ciborgue segue na subalternidade (Spivak, 2010), precisando ser salva, e sua redenção virá pelo masculino.

Uma vez finalizada a apresentação dos resultados deste estudo, passamos às considerações finais dele.

\section{Considerações Finais}

Este trabalho procurou refletir sobre a metáfora dos corpos em Haraway (2013, p. 36) para quem "um ciborgue é um organismo cibernético, um híbrido de máquina e organismo, uma criatura de realidade social e, também, uma criatura de ficção.”. Desse modo, foi proposto a seguinte questão-problema: quais as relações existentes entre mulheres trabalhadoras, em particular, secretárias, e as tecnologias em escritórios manifestas na ficção dos filmes? Dito isso, com esse estudo, foi possível perceber que a criatura de fíç̧ão e realidade social pode ser observada na história das mulheres e suas relações com as tecnologias desde sempre, mas especialmente em uma determinada profissão, como a de secretário/secretária, e pode também ser compreendida no cinema.

Esse é um exercício de compreensão sobre como ocorreu a fusão entre a imagem da mulher trabalhadora, notadamente a secretária, com o seu aparato tecnológico, e como essa fusão contribuiu para as novas identidades pós-humanas em que o corpo, o Ser e o Fazer, principalmente femininos, são inconcebíveis sem as suas extensões mecânico-tecnológicas. Trata-se, portanto, de contribuição para reflexões sobre uma temática que não se esgota neste trabalho. Foi um exercício de olhar o passado, considerando as artes do cinema, com vistas a perceber se isso ainda acontece em nossa atualidade.

Ao propor uma cisão e deslocamento entre as dualidades e dicotomias da mente-corpo, gênero, classe e raça, Haraway (2013) sugere em diversos exemplos que os construtos desses deslocamentos são observáveis também nas expressões artísticas e disso decorreram as nossas 
escolhas para esta pesquisa. Assim, as mulheres representadas nas ficções cinematográficas analisadas podem ser consideradas ícones ciborgues sob a perspectiva do Manifesto Ciborgue. Além disso, não se pode esquecer que mesmo nas artes é possível e necessário também desconstruir e construir novas formas da desobediência civil proposta por Plant (1999) e cujo maior desafio é promover a libertação das mulheres, ciborgues.

\section{Referências}

Baudrillard, J. (1991). Simulacros e Simulação. Lisboa: Relógio d'Água.

BBC. (2013). The arrival of women in the office. Recuperado em 20 maio, 2020, de http://www.bbc.co.uk/news/magazine-23432653

Beauvoir, S. (1980). O Segundo sexo. v. 1. Fatos e mitos. Rio de Janeiro: Nova Fronteira.

Benét, M. K. (1975). El ghetto de las secretarias. Barcelona: Editorial Kairós S. A.

Carvalho, R. O. (2016). Sociedade, Mulher e Profissão. R.G.Secr.,GESEC, 7(1), 27-44. doi: https://doi.org/10.7769/gesec.v7i1.396

Cineclick. (2013). A Datilógrafa. Ficha do Filme. Recuperado em 10 maio, 2020 de http://www.cineclick.com.br/a-datilografa

Estadão. (2019). Reclames do Estadão. Recuperado em 21 novembro, 2019, de http://blogs.estadao.com.br/reclames-do-estadao/tag/escrever/page/3/

Encantes. (2016). Filme: A Datilógrafa (Populaire, 2013). Recuperado em 05 junho, 2020, de https://encantes.blogspot.com/2016/06/filme-datilografa-populaire-2013.html

Garcia, C. C. (2011). Breve história do feminismo. São Paulo: Claridade.

Haraway, D. (2013). Manifesto Ciborgue: ciência, tecnologia e feminismo-socialista no final do século XX. In Kunzru, H. (org.). Antropologia do Ciborgue: as vertigens do póshumano. Belo Horizonte: Autêntica.

Marx, K. (1996). Os economistas. Recuperado em 21 abril, 2020, de http://www.histedbr.fe.unicamp.br/acer_fontes/acer_marx/ocapital-1.pdf

Montezuma, H. (1960). Manual da secretária moderna. Rio de Janeiro: Ediouro.

Moviepilot. (2013). Pôster do filme Populaire. Recuperado em 19 maio, 2020, de http://www.moviepilot.de/movies/mademoiselle-populaire/images

Natalense, L. (1998). A secretária do futuro. Rio de Janeiro: Qualitymark. 
Nye, A. (1995). Teorias feministas e as filosofias do homem. Rio de Janeiro: Record: Rosa dos Tempos.

Parafilia. (2020). In Priberam da Língua Portuguesa, recuperado em 05 junho, 2020, de https://dicionario.priberam.org/parafilia

Plant, S. (1999). Mulher digital: o feminino e as novas tecnologias. Rio de Janeiro: Record: Rosa dos tempos.

Peccin Junior, M. A. (2018). Revista Oitenta: Projeto Editorial e Cultura Política na Redemocratização (1979 - 1984). Dissertação de Mestrado, Universidade do Estado de Santa Catarina, Santa Catarina, SC, Brasil.

Perrot, M. (1998). Mulheres públicas. São Paulo: Fundação Editora da UNESP.

Perrot, M. (2005). As mulheres ou os silêncios da história. Tradução de Viviane Ribeiro. Bauru, SP: EDUSC.

Powertyping. (2013). Datilógrafa do início do Século XX. Recuperado em 25 maio, 2020, de http://www.powertyping.com/dvorak/keyboard.html

Puhl, P. \& Amaral, A. (2008). O feminino na tecnologia: uma proposta de leitura dos androides de Blade Runner a partir de Donna Haraway. Recuperado em 20 maio, 2020, de http://www.bocc.ubi.pt/pag/puhl-paula-amaral-adriana-feminino-na-tecnologia.pdf

Rainho, O. (1970). Curso de Secretariado Executivo. Rio de Janeiro: Fórum Editora.

Roinsard, R. (Direção). (2013). Populaire. [Filme cinematográfico]. França. Bélgica: Les Productions du Tresor.

Scott, R. (Direção). (1991). Blade Runner: o caçador de andróides. [Filme cinematográfico]. Los Angeles: Warner Brothers.

Sousa, K. F. (2006). Secretariado Executivo: uma perspectiva histórica da profissão. Dissertação de mestrado, Universidade Salvador, Salvador, BA, Brasil.

Sousa, K. F. (2017). Donas das dores no laço da verdade: violências contra mulheres trabalhadoras nos quadrinhos. Tese de doutorado, Pontifícia Universidade Católica de São Paulo, São Paulo, SP, Brasil

Spivak, G. C. (2010). Pode o subalterno falar? Belo Horizonte: Editora UFMG.

Wolf, N. (1992). O mito da beleza: como as imagens de beleza são usadas contra as mulheres. Rio de Janeiro: Rocco.

Zuin, D., \& Findlay, P. (2014). Reflections on secretarial work and issues for further studies: a conceptual contribution. R.G.Secr.,GESEC., 5(3), 28-48. doi: https://doi.org/10.7769/gesec.v5i3.331 
Submetido em: 05.06 .2020

Aceito em: $\quad 18.09 .2020$ 